\title{
PICASSO EN BARCELONA
}

\section{Alicia Azuela}

Picasso llegó a Barcelona en mil ochocientos noventa y cuatro, cuando tenía solamente catorce años. Con la precoz independencia que le era típica, supo aprovechar desde el primer momento, el carácter cosmopolita propio de Barcelona para elegir de ahi el ambiente intelectual que podía ofrecer mayores posibilidades a su vocación artística. Gracias a ello le fue posible vencer las presiones de su padre que queria que a semejanza de él se convirtiera en pintor académico.

De entre todos los grupos de intelectuales que convivían en Barcelona, $\mathrm{Pi}$ casso escogió al de los modernistas catalanes, quienes lo iniciaron en el mundo mágico del simbolismo, abriéndole las puertas al camino que le permitiría expresar en forma independiente su creatividad Con los modernistas catalanes, Picasso al mismo tiempo que descubrió un nuevo mundo dentro del universo del arte, fue por primera vez consciente de la realidad histórica que España entonces vivía.

La familia del artista estaba muy poco politizada ya que muchos de los miembros de la clase media que dependian económicamente del presupuesto gubernamental, sostenían una postura política contradictoria. Eran conservadores porque de la estabilidad económica del gobierno dependía su propio equilibrio a la vez que participaban de la actitud fatalista e inconforme que entonces reinaba en España como consecuencia de la crisis histórica por la que entonces pasaba el país.

En enero de 1898 España fue forzada a firmar la independencia de Cuba y ceder sus colonias de Puer to Rico y Filipinas a los Estados Unidos Esta derrota impactó profundamente a los españoles que desde la restauración de la monarquía en 1873, habían tomado una actitud de desilusión y nostalgia frente a la pérdida de su poderío internacional. Este estado de ánimo se agudizaba cada vez más ante la ineptitud del gobierno para solucionar el alarmante estado de injusticia y pobreza en que vivían obreros y campesinos y la creciente bancarrota en la que se encontraba el país.

Como consecuencia de estas circunstancias hubo una fuerte reacción dentro del mundo intelectual, que se manifestó en el deseo de devolver a España la grandeza revitalizando el espíritu de su gente. Fueron la generación del 98 y el grupo modernista catalán los principales representantes de esta reacción.

Entre los miembros más prominentes de la generación del 98, estuvieron; Unamuno, Azorín y Ortega y Gaset Al igual que el resto del grupo, buscaban darle a España una nueva personalidad llena de fuerza y naturalidad a través de revitalizar sus valores espirituales contenidos en la tradición y el arte. Consideraban que en la nueva fisonomía de su patria debía reinar un espiritu de unanimidad que a la vez que supiera respetar las diferencias regiona- 
les lograra unificar al país como nación

Por su parte los modernistas catalanes, estaban también a favor de la defensa del espíritu español, pero a diferencia de la generación del 98 en vez de ser nacionalistas eran separatistas y cosmopolitas. El tradicional espiritu secesionista catalán agudizado notablemente por las circunstancias históricas entonces existentes, buscaba más que nunca afirmar su identidad integrándose a la cultura cosmopolita del resto de Europa en vez de ir únicamente a las tradiciones locales surgidas en España. Pensaban ellos que el quedarse en ese nivel, podría hacerlos caer en un provincialismo que los aislaría de los avances culturales del resto del continente impidiendo su propio desarrollo.

Apoyaban políticamente esta actitud con una gran simpatía por el anarquismo, movimiento que apareció ante sus ojos como el instrumento más adecuado para lograr la reconstrucción regional de Cataluña, después de haber exterminado el institucionalismo madrileño que los tenía sujetos.

Picasso se integró al grupo modernista en 1898. Este estaba formado por Isidro Nonell, Miguel Utrillo, Ramón Casas, Sebastián Junyer Vidal, Manolo, Ángel y Mateo Soto, Ángel Sabartes, Joan Maragallas y Santiago Rusiñol. El poeta Maragallas lo introdujo al pensamiento nitcheano con su burla hacia la burguesía filistea, su actitud fatalista hacia la vida y la convicción en la necesidad de destruir los valores actuales para construir a cambio un mundo feliz. Gracias a él, Picasso conoció a Rimbaud, Verlaine, y Mallarmé, además de familiarizarlo con la tesis de Schopenhauer sobre la naturaleza como apariencia

A través del contacto con estas ideas principió a dudar de las posibilidades que el realismo academicista podría ofrecerle, e inició la búsqueda de su expresividad artística a través del mundo de los símbolos. Ya puestos los ojos en otra forma de realidad compartió el amor simbolista hacia lo exótico, la pasión prerafaelita por el arte medieval, y el deseo modernista de volver los ojos al arte antiguo español, interesándose profundamente por el arte románico, medieval y renacentista de su país. Manifestaciones que fueron más tarde determinantes para su obra cubista

En aquellos años, el poeta Santiago Rusiñol era el organizador de las festividades modernistas. En ellas puso en escena varias de las obras teatrales de Mätterlinke, éstas se ofrecían como homenaje público al Greco, pintor considerado por ellos como el mejor artista español. El contacto que Picasso tuvo entonces con la obra del Greco (lámina 1) fue definitivo, ya que ejerció durante muchos años una gran influencia sobre él, así por ejemplo, el uso manierista de las formas, su desesperada actitud ante la vida y el sentido metafórico de su arte estuvieron presentes en él a todo lo largo del periodo azul. Típicos ejemplos son "El viejo y la joven", "El Asceta"y "El ciego". (lámina 2)

Como parte del grupo modernista e influenciado por los prerafaelitas, Picasso se sintió atraido hacia lo enfermizo y lo grotesco, viendo al amor y la muerte como sinónimos (lámina 3), manera esta de percibir la vida que estu- 
vo presente en su pintura de tipo erótico y político. Al igual que los simbolistas franceses Picasso y su grupo sintieron una gran admiración por Moreau, Redon, Carriere, Puvis de Chavanis y Munch, al mismo tiempo que una especial predilección por Van Gogh, Gaugin y Tolouse Lautrec.

Sentían todos ellos una gran identificación con el pobre (lámina 4) y el marginado, el bohemio, el hombre de circo (lámina 5) y el ciego. Influenciados por Nonell, Hoysmann Alexandre Steinfer y los prerafaelitas habían unido su conmisericordia por el desposeido a la idea de que la deformidad y la decrepitud eran símbolos de espiritualidad

Políticamente, Picasso como el resto de los modernistas catalanes, era simpatizante del grupo anarquista catalán dirigido entonces por Alesandro Lerrux. Como ellos, creían en una sociedad sin Estado y sin propiedad privada, donde fuera inexistente todo tipo de sistema político institucional que en tanto institucional, sería por sí mismo generador de pobreza e injusticia.

Para entonces el anarquismo había adquirido gran fuerza en Europa, teniendo aterrorizado el viejo continente debido a su agresividad y extremismo. Durante esos años habían puesto más de cien bombas en lugares públicos y para 1909 habían matado a seis jefes de Estado europeos.

Barcelona estaba especialmente influída por el anarquismo debido principalmente a los conflictos de clase que entonces tenían entre sí industriales, burócratas y trabajadores, grupos sociales más importantes de la ciudad Los industriales, al mismo tiempo que luchaban por independizarse económicamente de Madrid combatían por estabilizar el sistema capitalista español Los burócratas, al depender de Madrid buscaban a toda costa mantener sus ligas con la capital. El proletariado, por su parte formado por campesinos pobres emigrados del sur del país, vivía en pugna con burócratas e industriales Los primeros abusaban de ellos en tanto representantes del poder central de Madrid, mientras que los segundos los explotaban a nivel laboral.

Eran precisamente los obreros y los intelectuales, grupo minoritario pero también marginal, quienes se sentian atraídos por el anarquismo. El trabajador, sin conocer de manera directa este movimiento sabía de su gran promesa "La exterminación de todo tipo de autoridad porque ésta en sí mismo traía el germen de la injusticia y la pobreza". Los intelectuales por su parte, se habian convertido al anarquismo a través de la lectura de Kropotkin y Bakunin, compartían con los trabajadores el pesimismo frente a la realidad histórica y la convicción en la necesidad de destruir totalmente el sistema social, para poder llegar a una solución de los problemas individuales y sociales.

Aunque ambos grupos se decian anarquistas, la forma en que cada uno se involucró en este movimiento fue esencialmente distinta. Los intelectuales colaboraban a un nivel meramente teórico difundiendo los principios anarquistas a través de artículos, conferencias o meras pláticas de café. Los trabajadores por su parte eran generalmente carne de cañón en las batallas callejeras y actos de terrorismo

Igual que otros intelectuales, Picasso limitó su acción política como anar- 
quista a la asistencia a manifestaciones, mítines y reuniones. Sin embargo se definió a sí mismo como tal, en tanto que estaba por la destrucción del orden social, opresor de pobres y artistas. Y creía en un arte que al generar constantemente nuevas alternativas pusiera en crisis el orden establecido ofreciendo a cambio distintas formas de vida. Esta idea trascendió sobre su obra dándole el tono anárquico e individualista que siempre la caracterizó *

Al igual que los modernistas y la generación del 98 pensaba que era precisamente con su obra que los intelectuales debían involucrarse en la realidad histórica. Cosa que hizo expresando en su arte los sentimientos e ideas de su tiempo, su grupo y de aquellos con quienes de alguna manera se sentía solidario. Buen ejemplo de esta actitud es el dibujo "Entre dos gendarmes". (lámina 6), apunte hecho al vivo con gran influencia de Daumier y Munch (lámina 7).

Durante esta época el pintor catalán Isidro Nonell influyó más que ningún otro sobre su obra e ideas políticas y artísticas. Nonell, hombre de recias convicciones fué el primer artista español de ese tiempo que pintó al pobre con realismo y simpatía, en vez de representarlo como el pícaro pordiosero, figura muy socorrida dentro de la tradición pictórica española al hacer referencia a la pobreza. Fue él quien despertó en Picasso el deseo de denunciar la injusticia a través de su obra. Gracias a esto comparecieron juntos entre los pocos pintores contemporáneos no germánicos seguidores de la tradicción artística europea interesada en representar con realismo a pobres y marginados. La ascendencia que formalmente tuvo Nonell sobre la obra de Picasso se puede percibir en obras como la serie de estudios de cretinos (lámina 8) o "grupo de pobres" (lámina 9). Hacía uso en ellos de las posibilidades expresivas de las deformaciones corpóreas y del empleo de siluetas muy simplificadas, elementos que Picasso utilizaria más tarde en su periodo azul (lámina 10)

La fascinación que tuvo siempre por el arte primitivo también principió al lado de Nonell. Este lo introdujo al gran culto que entonces rendían los modernistas catalanes a lo primitivo. En su veneración había la esperanza de que en lo primigenio estuviese la solución a los problemas que entonces acosaban a España. En este culto no estaban solos ya que era a la vez parte de toda una reacción de la intelectualidad europea en contra del mecanicismo y despersonalización del mundo moderno.

En Barcelona el primitivismo se manifestó con el redescubrimiento de viejas canciones populares, el gusto por el arte ibérico, romántico, medieval y renacentista, al igual que por la literatura española antigua. Influencias muy presentes en la obra poética de Rusiñol y Maragallas y en pinturas como "niño sosteniendo una paloma" (lámina 11) de Picasso

El año de 1901, Pablo Picasso fundó junto con Francisco Soler la revista "arte joven", publicación en la que por vez primera trabajaron de manera

\footnotetext{
* Cabe sin embargo considerar que junto a este anarquismo hubo siempre en Picasso un gran respeto por el arte del pasado, estando este siempre presente en su obra a manera de remembranza o mera recapitulación
} 
conjunta los modernistas catalanes y la generación del 98 . En ella quedo plasmado como un todo el pensar de la intelectualidad española de finales de siglo; pensar que al manifestarse de manera conjunta buscaba unir esfuerzos para salvar a España y como afirmara entonces Unamuno "devolver al español la frescura del niño y de sus ancestros" "Entre los principales colaboradores de la revista estuvieron Pío Baroja, Azorín, Martínez Ruiz y Unamuno.

Como director artístico de la revista, Picasso diseñó las portadas e ilustró mucho del material literario. Tal es el caso de los "sonetos" de Miguel Unamuno, "La orgía macabra" de Pío Baroja y la traducción de la obra de Goethe "nuestra única estética". La pintura y obra gráfica entonces realizada por Picasso tuvo un sentido de crudeza y sarcasmo mucho mas pronunciado que el de su producción catalana. Estos rasgos fueron comunes a todos los miembros de "Arte joven", como parte de su inconformidad frente a la realidad histórica "Obras de Picasso típicas de entonces son "La Mujer en azul" (lámina 12), "El portal" y "Bailarín enano".

No obstante haber sido muy breve la duración de "Arte joven" fue ésta una experiencia trascendental en su vida ya que por ella pudo analizar y compartir con otros intelectuales españoles las reacciones provocadas por los problemas políticos de su patria

Fue precisamente después de haber vivido esta experiencia que Picasso decidió irse a vivir a París. Aparentemente la posibilidad de elegir entre nacionalismo y localismo, cosmopolitanismo y regionalismo le parecieron limitadas Sin embargo con esta decisión no renunció a su hispanidad e hizo a España presente en la persistencia de rasgos artísticos propios a su tradición y en su postura politica, prueba de ellos es "Guernica" obra típica del ingenio ibero. 


\section{BIBLIOGRAFIA}

BARR, Alfred H Picasso Fifly Years of His Art, The Museum of Modern Art. New York, 1946. BARR, Alfred H. Cubism and Abstract Art, The Museum of Modern Art. New. York, 1966 BERGER, John. Suctess and Failure of Picasso, Penguin Books, Inc., Baltimore, Maryland, 1965. BERGER, John. The Moment of Cubism, Pantheon Books, 1969

BLUNT, Anthony and Poebe Pool Picasso and the formative Years, Studio Vista, London, 1962.

BLEIBERG, German and E. INMAN Fox. Pensamiento y letras en la España del siglo XX, Edit Seix Barral, 1970 .

BARMANN SIE, Coustav Reinterpretación del Modernismo, Vanderbilt University Press, 1966 BLANCO AQUINAGA, Carlos Juventud del 98, Siglo Veintiuno, Edit. 1970

DÍAZ PLAJA, Guillermo. A History of Spanish Literature, University Press, 1971

FABRE, José y PALAVI Picasso en Cataluña, Ediciones Poliglota, S. A, 1966, Barcelona

GANIVET, Ángel. Ide a rum, Español Aguilar, S. A, 1964.

GOLDING, John. Cubism a History and an Analysis, Art News vol 71, September 1962, pp. 20-29, October 1972 pp. 38-50

KOZLOFF, Max Cubism and The Human Comedy, Art New, 70 th Anniversary issue, September 1972, pp $35-41$

PENROSE, Roland. Picasso His Life and Work, Icon Editions, Harper and Row Publishers, 1973. 
DOI: http://dx.doi.org/10.22201/iie.18703062e.1982.50\%20Tomo\%202.1146

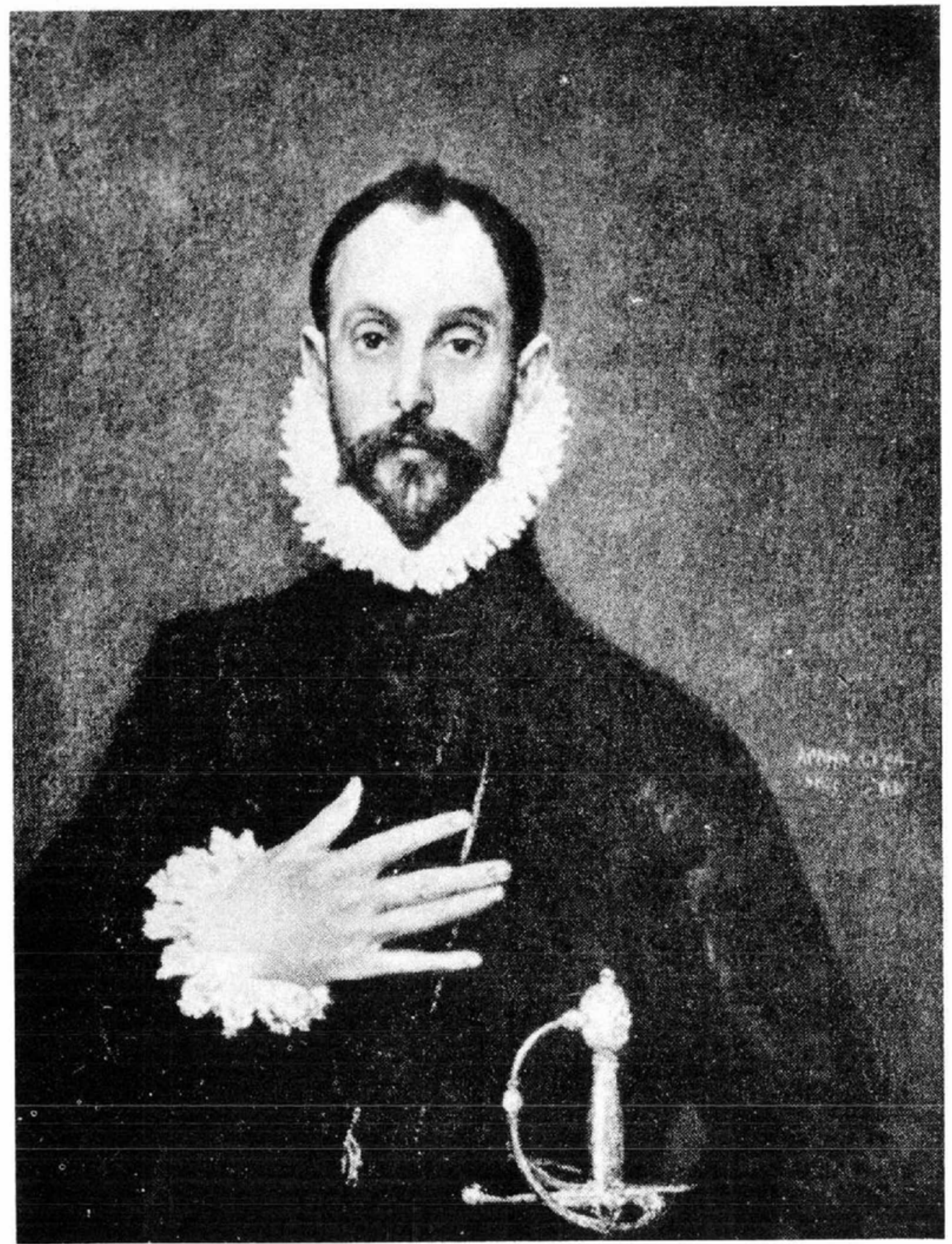

Lámina 1. El Gireco. Itombre com la mano al peiho. Óleo. Museo del Prado, Madrid. 
DOI: http://dx.doi.org/10.22201/iie.18703062e.1982.50\%20Tomo\%202.1146

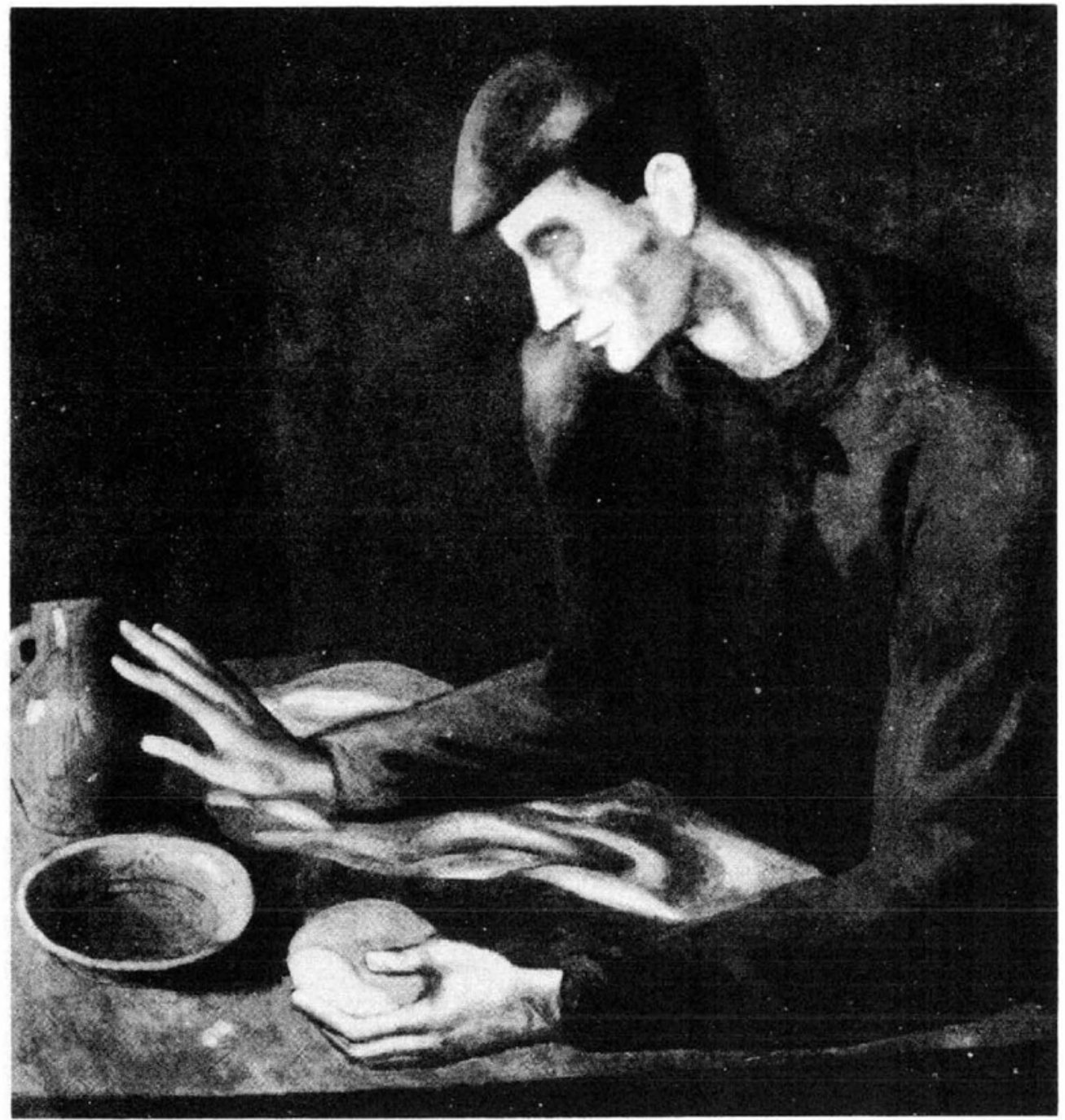

Lámina 2. Picasso. El ciego, 1903. Óleo. Museo Metropolitano de Nueva York. 


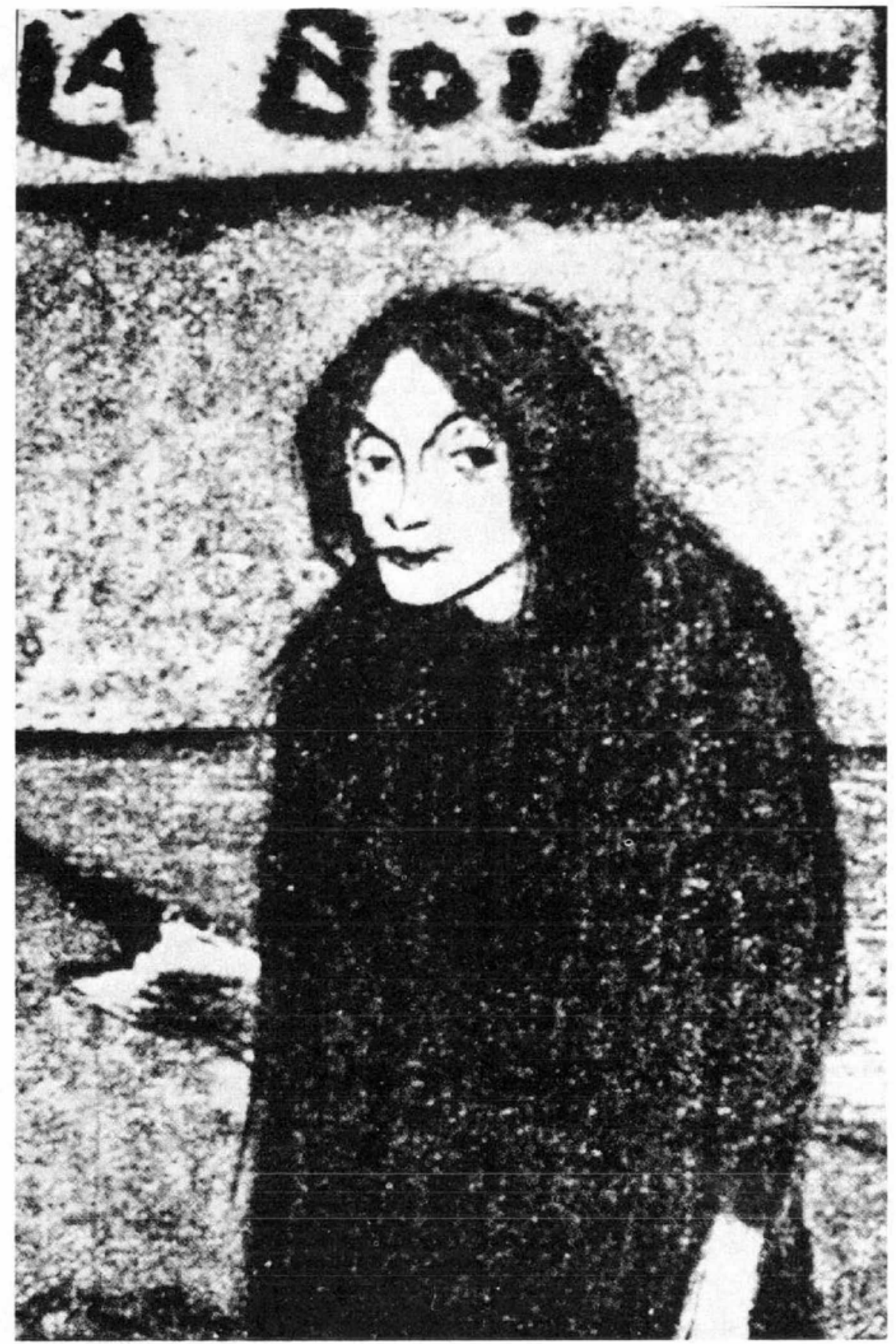

Lámina 3. Picasso. Ilustración para La Loca de Surinyas Senties, publicada por la revista Ciataluña Artístia, el 16 de septiembre de 1900. Barcelona. 
DOI: http://dx.doi.org/10.22201/iie.18703062e.1982.50\%20Tomo\%202.1146

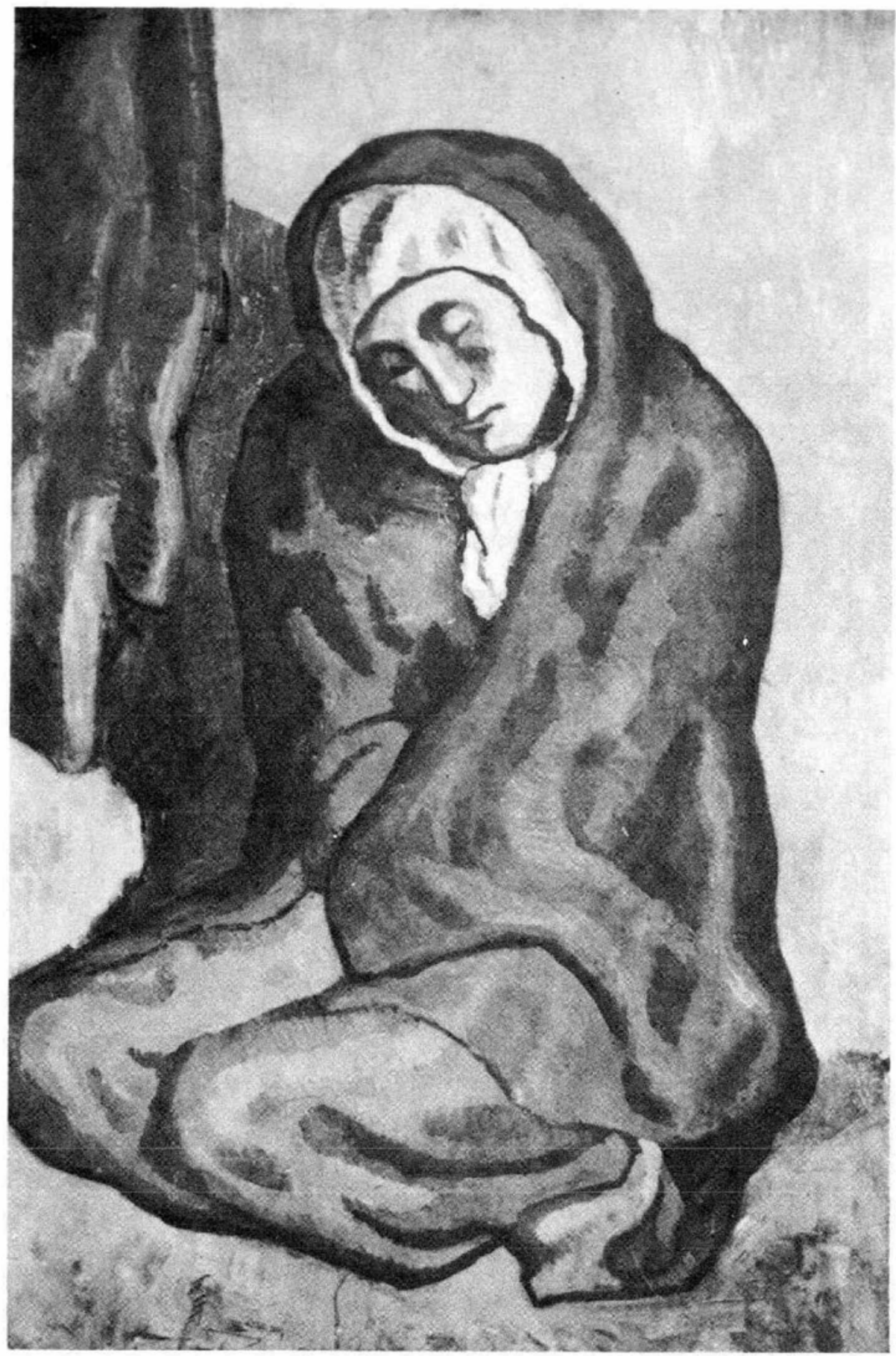

Lámina 4. Picasso. La pobre acurrucada, 1902. Óleo. The Art Gallery. Toronto. 
DOI: http://dx.doi.org/10.22201/iie.18703062e.1982.50\%20Tomo\%202.1146

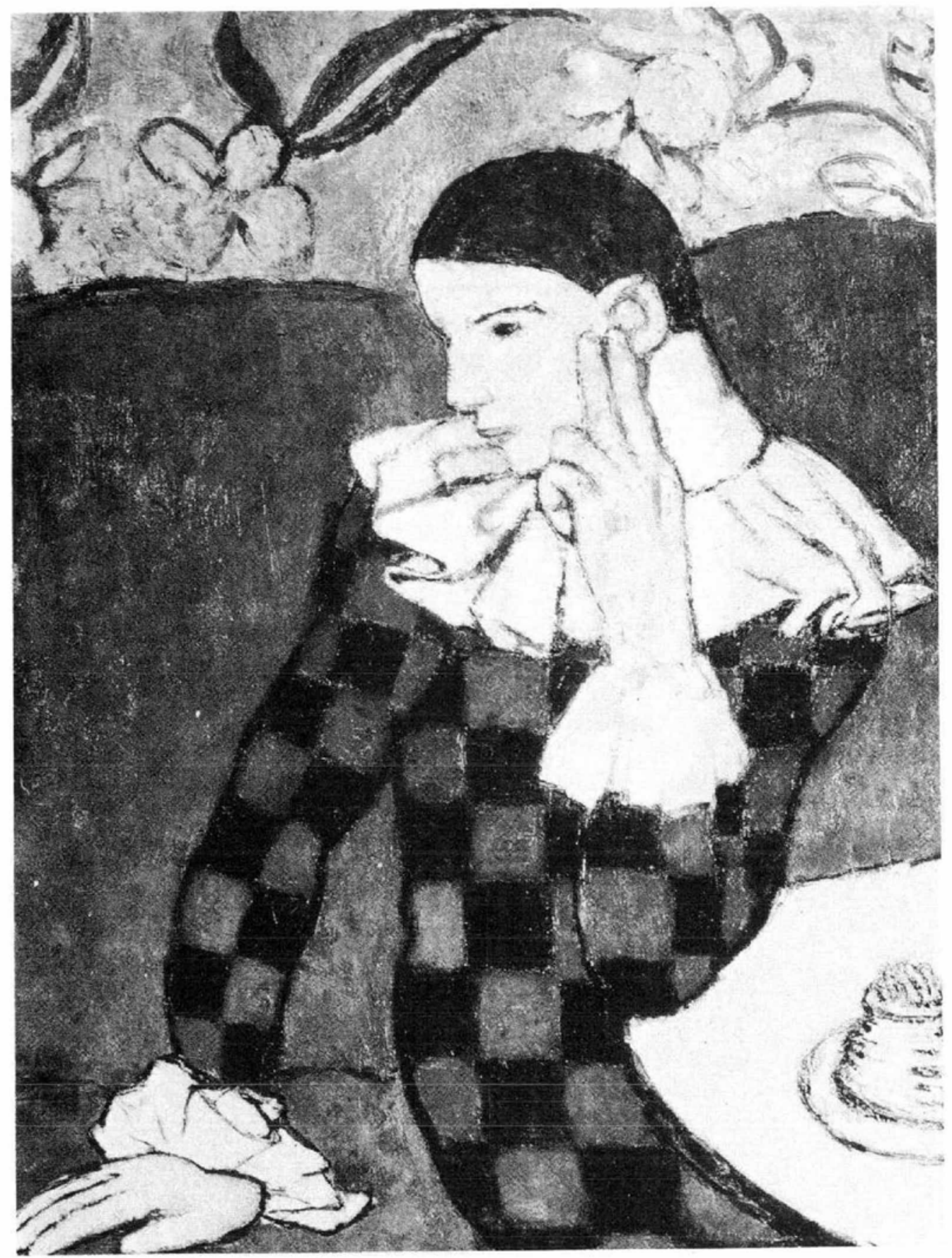

Lảmina 5. Picasso. Arlequín acodado, 1901. Óleo. Museo Metropolitano de Nueva York. 


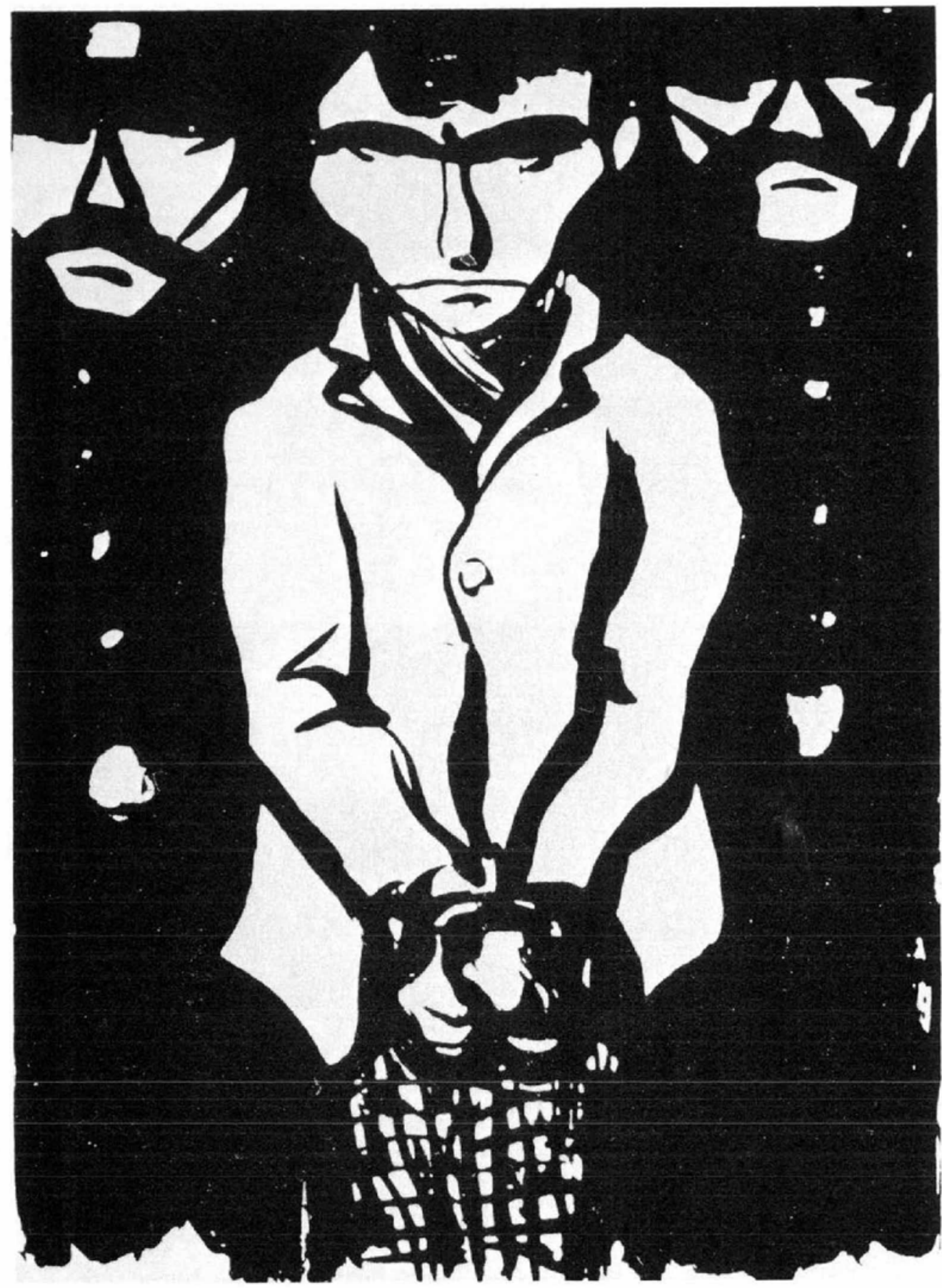

Lámina 6. Picasso. Hombre con dos gendarmes, wash, 1901. 


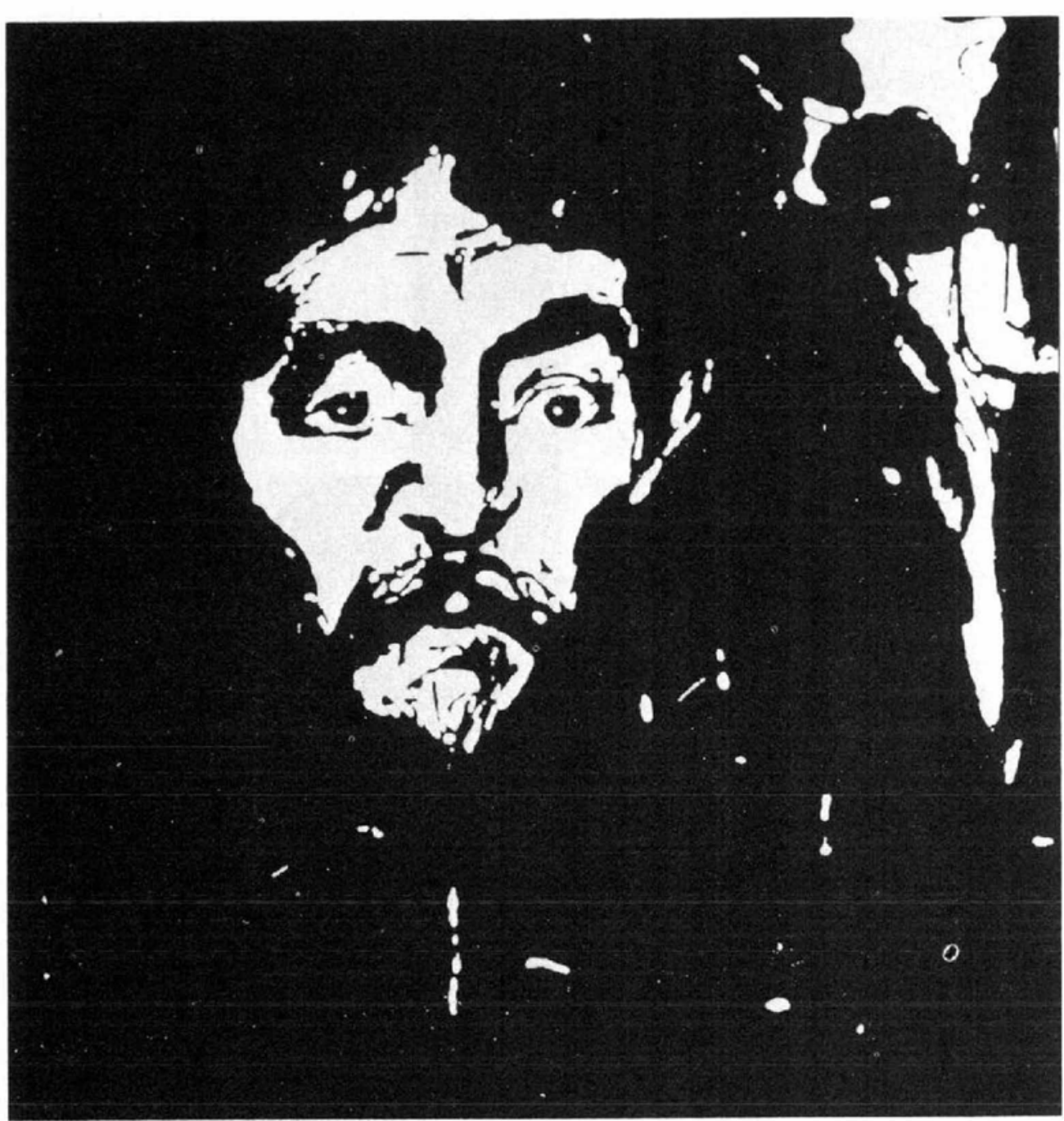

Lámina 7. Eduard Munch. Detalle de Jelousy, grabado en madera. Colección Meyer. Billedgalleri. Bergen. 
DOI: http://dx.doi.org/10.22201/iie.18703062e.1982.50\%20Tomo\%202.1146

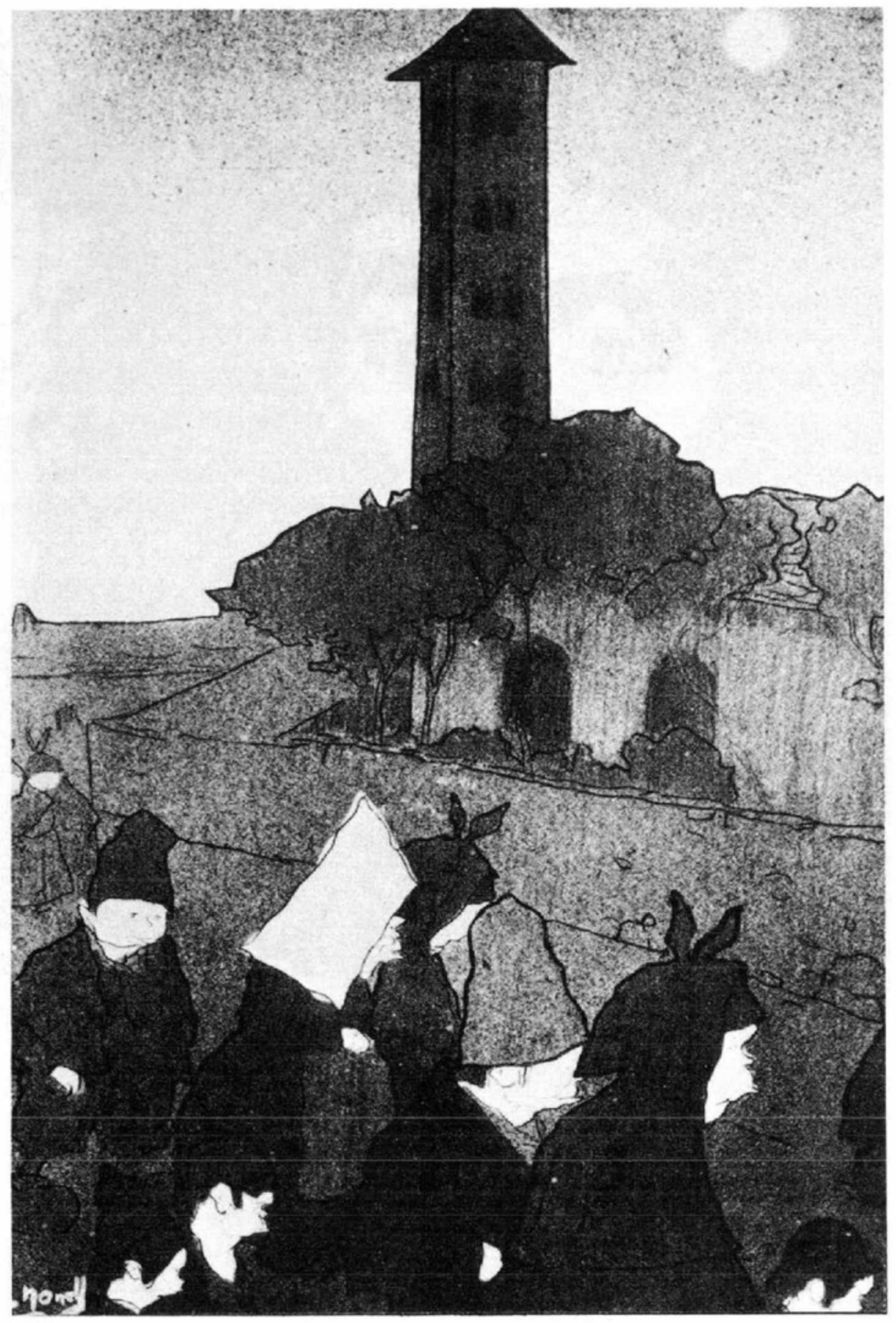

Lámina 8. Isidro Nonell, 1896. Cretinos de Bohi, dibujo a lápiz. Colección de Ricardo Vinés, París. 


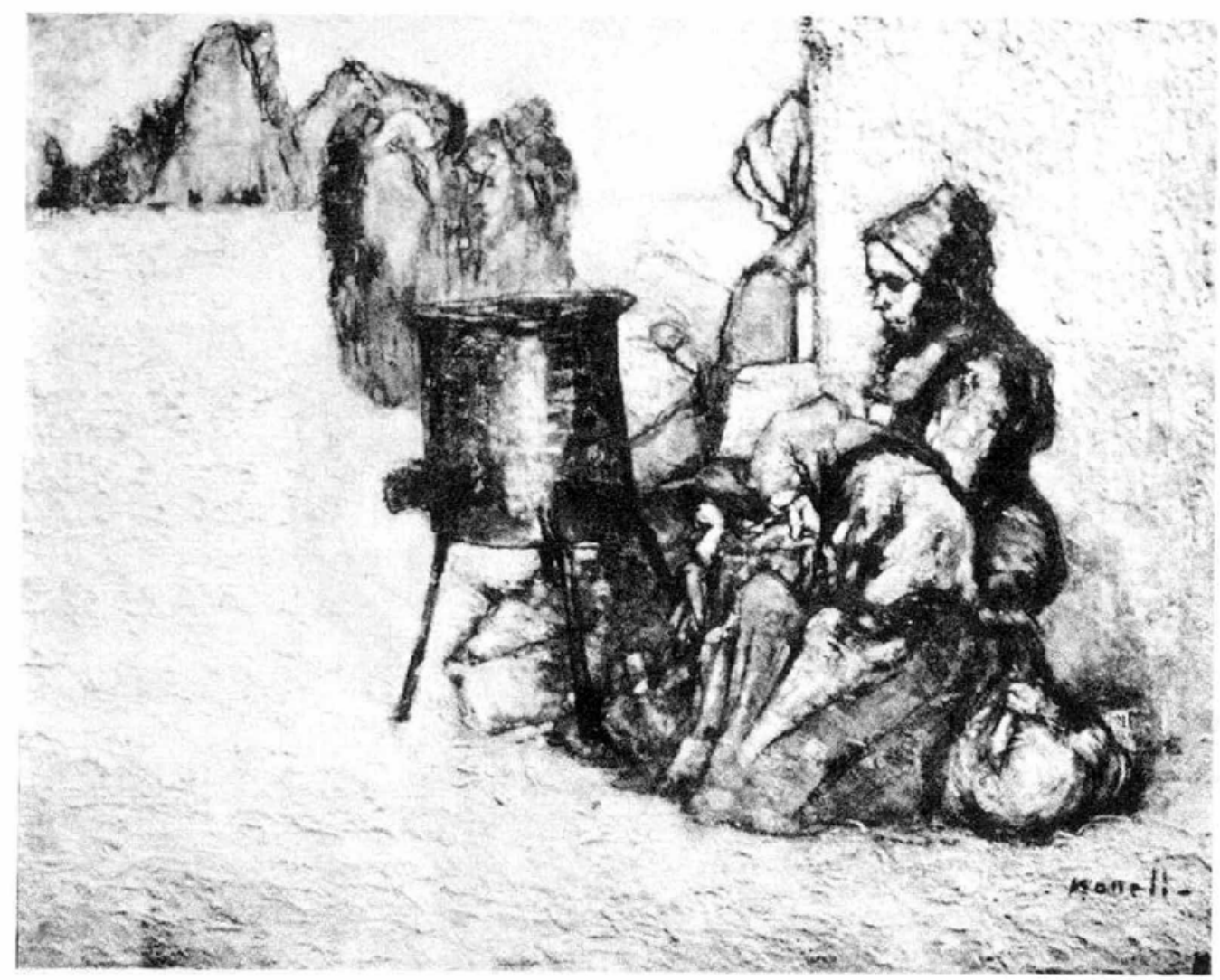

Lámina 9. Isidro Nonell. (inupo de pobres, dibujo a lápiz. Colección de José Salas. Barcelona. 
DOI: http://dx.doi.org/10.22201/iie.18703062e.1982.50\%20Tomo\%202.1146

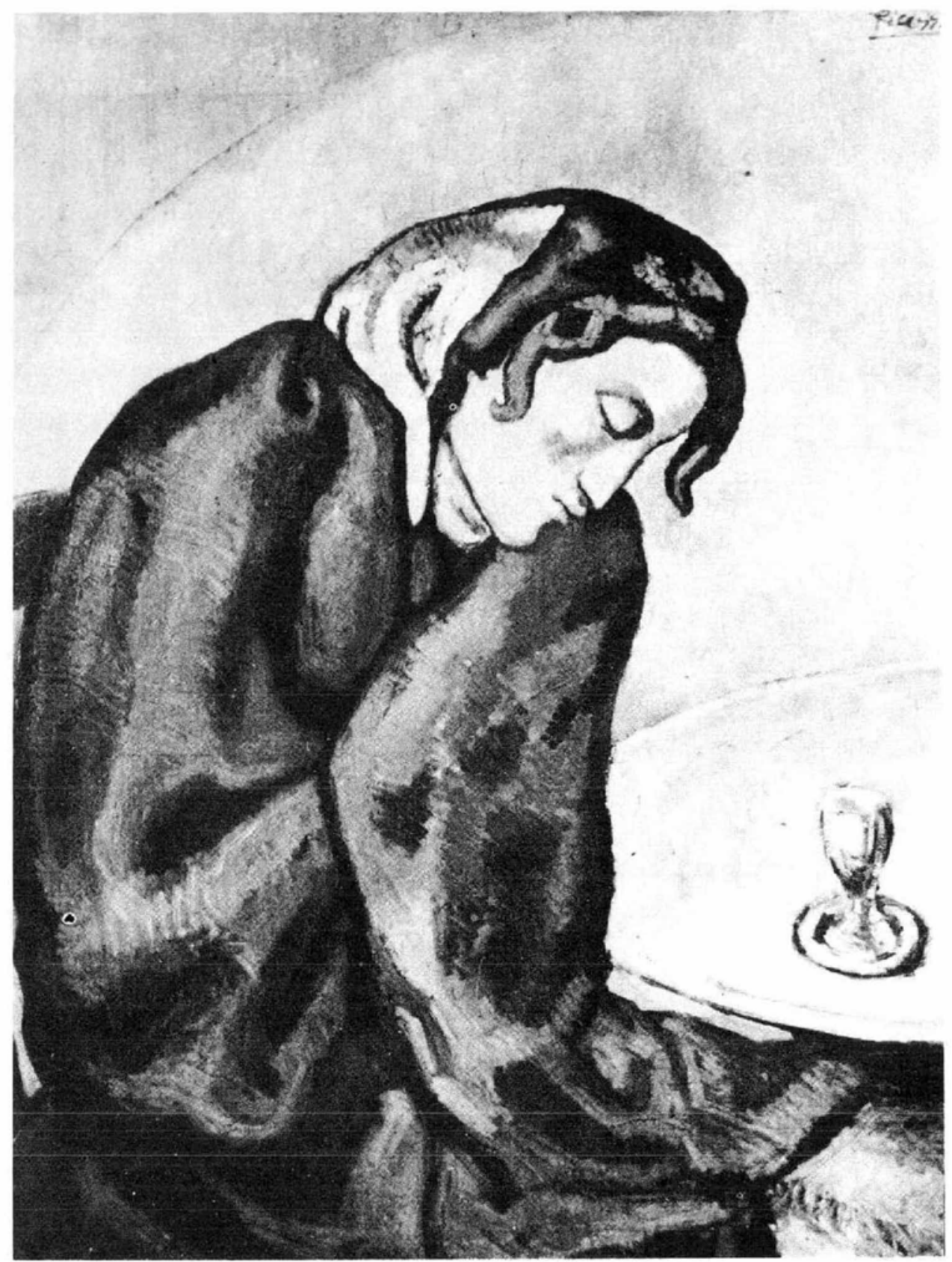

Lámina 10. Picasso. Bebedora adormecida, 1902. Óleo. Colección Dr. Huber Glarus, Suiza. 
DOI: http://dx.doi.org/10.22201/iie.18703062e.1982.50\%20Tomo\%202.1146

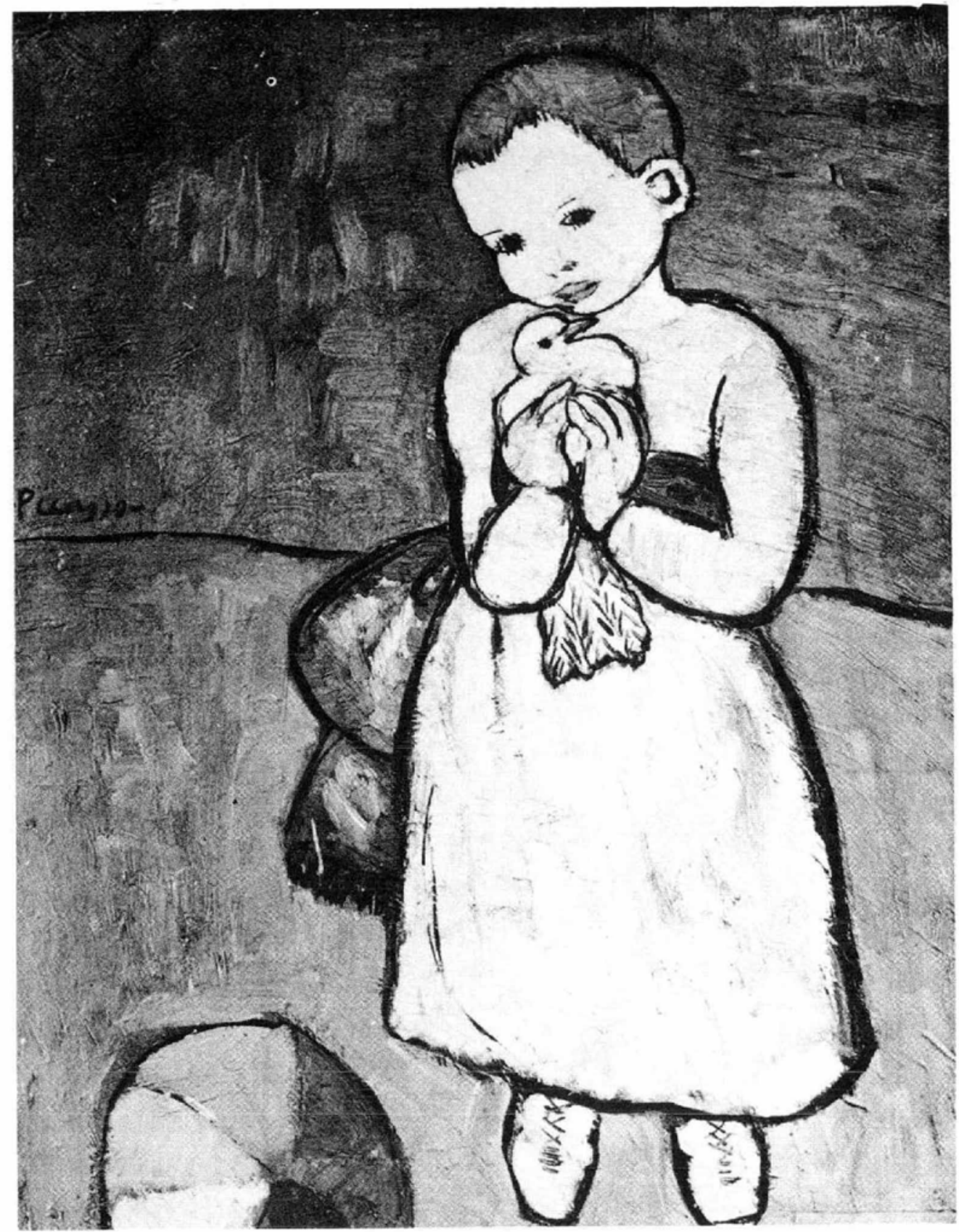

Lámina 11. Picasso. Niño sosteniendo una paloma, 1901. Óleo. National Gallery, Londres. 


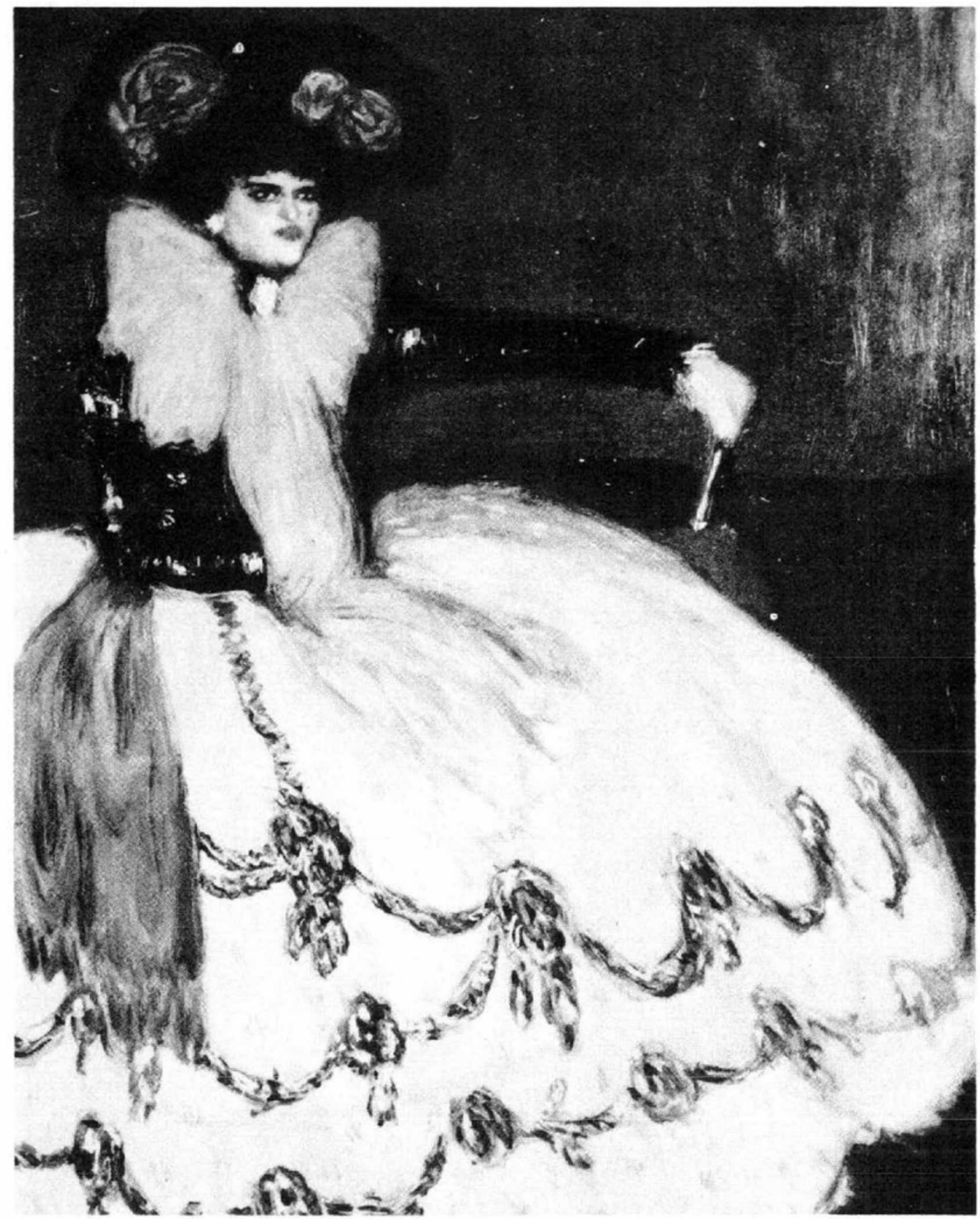

Lámina 12. Picasso. Mujer en azul, 1901. Óleo. Museo Nacional de Arte Moderno. Madrid. 